\title{
RECEPÇÃO: \\ A ABORDAGEM DOS ESTUDOS CULTURAIS
}

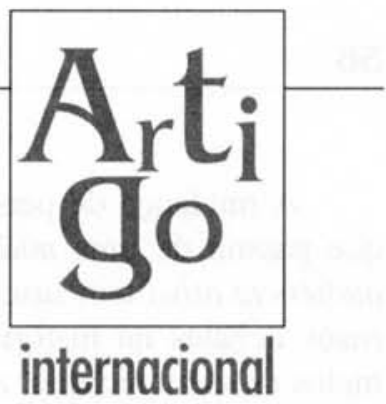

\section{Nas últimas décadas, ganharam relevância os estudos relativos à recepção dos meios de comunicação ou, como prefere o autor, estudos sobre as audiências. Destaca-se, nesta tendência de pesquisa, o aspecto de que os leitores, os telespectadores, os radiouvintes não são mais tratados como consumidores passivos dos meios de comunicação. São abordados, agora, como receptores capazes de ter leituras diferenciadas e plurais das mensagens veiculadas, buscando sentidos convergentes às suas experiências de vida.}

Este artigo tem por objetivo apresentar aos leitores, mesmo que de maneira sintéti$\mathrm{ca}$, o percurso feito pelos estudos em Comunicação a respeito do tipo de resposta que os leitores, telespectadores e radiouvintes, ou seja, a audiência, os receptores dos meios de comunicação, dão às mensagens a que têm acesso.

Durante os anos 70, os estudos voltados para essa área de interesse variavam muito: tanto destacavam os efeitos produzidos pelas mensagens veiculadas pelos meios de comunicação quanto enfocavam a seleção da programação de acordo com seus usos e gratificações $^{2}$. A partir de meados dos anos 80 , tem ocorrido um movimento diferente, mais direcionado para as pesquisas que ana- lisem os significados que as audiências efetivamente constroem sobre as mensagens da mídia. Estudos demonstram, por exemplo, que a audiência do seriado Dallas, em Israel, e a audiência desta mesma série nos Estados Unidos têm interpretações muito diferentes. Pesquisas também comprovaram que a audiência inglesa da popular série da $B B C$ East Enders ( $O$ pessoal da Zona Leste) varia enormemente em suas acepções e interpretações dos mesmos episódios.

\section{O AUTOR}

\section{Robert A. White}

Professor do Centro de Estudos Interdisciplinares de Comunicação da Universidade Gregoriana, Roma, Itália.

1. Neste número, Comunicação \& Educação traz, com exclusividade em língua portuguesa, a primeira parte deste artigo sob o título Audience interpretation of media: emerging perspectives (Interpretação da audiência da mídia: perspectivas emergentes). As outras partes serão publicadas nas próximas edições. Artigo originalmente publicado em Communication Research Trends. Saint Louis University, v. 14, n. 3, 1994. p. 3-13.

2. Usos e gratificações: linha de pesquisa dos meios de comunicação originária do estrutural-funcionalismo, desenvolveu-se nos EUA. Essa concepção de pesquisa destaca o papel do receptor como selecionador dos produtos culturais da mídia. Portanto, o destinatário faz uso das mensagens a partir de seu contexto sociopsicológico. A satisfação das necessidades dos receptores é vista em termos das funções sociais que exercem. Mais sobre o assunto ver: WOLF, Mauro. Teorias da comunicação. 2.ed. Lisboa: Presença, 1992 e MATTELART, Armand. Historia de las teorias de comunicación. Barcelona: Paidós, 1996. (N.Ed.) 
A mudança de perspectiva de análise que passou de uma mídia ativa para uma audiência ativa tem suscitado os mais calorosos debates na história dos estudos dos meios de comunicação. A expressão Teoria da Recepção tem sido usada por muitos para caracterizar essa abordagem no estudo de audiência, mas consideramos que seria mais apropriado chamá-la Teoria da Interpretação da Audiência³.

A Teoria da Interpretação da Audiência tem se desenvolvido amplamente nos últimos anos, seguindo a tradição dos Estudos Culturais de pesquisa dos meios e reflete os debates e as diferentes escolas de pensamento que têm procurado interpretar qual o uso que as audiências fazem das mensagens da mídia. Comum a todas as diferentes abordagens e linhas teóricas, no entanto, é a premissa de que o uso e os efeitos da mídia devem ser estudados no que se refere às construções subjetivas de significados, tanto a construção atribuída à mídia quanto as que são desenvolvidas em resposta à mídia. $\mathrm{A}$ metodologia mais utilizada nas pesquisas interpretativas de recepção é um tipo de etnografia ${ }^{4}$ da audiência, que requer do pesquisador a reconstrução do significado da mídia a partir da perspectiva do sujeito. Apesar de a expressão Teoria da Recepção ser amplamente utilizada nos estudos dos meios de comunicação, pode-se mais acuradamente referir-se a ela como Teoria Interpretativa, porque estes estudos estão mais voltados para a interpretação que as audiências fazem do significado dos produtos cul- turais veiculados pela mídia do que para os efeitos comportamentais estimulados pelos meios de comunicação.

Em primeiro lugar, cabe ressaltar que a Teoria da Interpretação de Audiência se fortaleceu muito devido ao pouco êxito de pesquisas empíricas que têm como premissa verificar os efeitos, previstos ou direcionados, que a mídia causa às audiências e se esses efeitos são resultado do poder de persuasão psicológica ou de coerção ideológica que a mídia possui.

Como exemplo, pode-se citar pesquisas nas quais os entrevistados respondem a questionários fechados sobre o quanto de efeito uma mensagem da mídia produz sobre eles. $\mathrm{O}$ resultado desses questionários tem mostrado que alguns dos efeitos esperados pelos pesquisadores sempre aparecem nas respostas. No entanto, quando os entrevistados respondem livremente, ou seja, não seguindo um questionário, dão uma imensa variedade de interpretações que não cabem em modelos teóricos prévios, sejam eles psicológicos ou sociais.

Em segundo lugar, a Teoria Interpretativa é produto de valores sociopolíticos de teóricos que acreditam que as audiências participam efetivamente da construção da cultura e que a prioridade das pesquisas deve ser a compreensão da ação dos leitores, espectadores, ouvintes, tendo como base a necessidade de uma política de democratização dos meios de comunicação. Em

3. O autor faz sua opção no quadro de uma polêmica entre os estudiosos da Comunicação. Os defensores de Recepção estão entre aqueles que aceitam tal denominação por ela ser capaz de abarcar o processo comunicativo geral. É a expressão que tem sido adotada por pesquisadores e estudiosos brasileiros, principalmente nas duas Instituições Científicas mais respeitadas Intercom e Compós - e que anualmente têm apresentado trabalhos sobre o assunto. Outros pesquisadores preferem o termo audiência devido à forte tradição funcionalista de pesquisas empíricas, principalmente norte-americanas, na área. (N.Ed.)

4. A etnografia relaciona-se com a Antropologia. Tem dado contribuiçōes à Comunicação e consiste em uma abordagem metodológica que coloca o sujeito-receptor como objeto preferencial da pesquisa. A etnografia tem ajudado a conhecer as práticas sociais dos sujeitos-receptores ou das audiências, através das técnicas da observação participante, das histórias de vida, anotações do caderno de campo etc. (N.Ed.) 
terceiro lugar, o desenvolvimento de políticas nacionais que tiveram como premissa o uso centralizado e controlador da mídia para reeducar a população e integrar rapidamente os cidadãos a um sistema nacional único, tem resultado em desastres notórios, não importando quanto idealista seja a concepção de sociedade que se tenha. Tais resultados têm levado a propostas políticas baseadas em concepções nada confiáveis sobre os possíveis interesses da audiência e sobre as suas prováveis construções culturais de significados. Finalmente, todos aqueles que têm interesses na mídia mais voltados para a diversão, para a estética e para o prazer da cultura popular e do entretenimento popular acham a concepção de criação de valores sociais pela mídia simplesmente repugnante, não-humana, pomposa e, em última análise, irrelevante. Argumentam dizendo que, se se está lidando com um meio de entretenimento, por que não começar a se questionar sobre as causas e as maneiras como as pessoas encontram prazer na mídia?

Estabelecidas as questões que se constituíram em elementos fundamentais ao desenvolvimento da Teoria Interpretativa, pode-se apontar quatro de suas abordagens com origem nas diversas tradições disciplinares ou na influência de contextos sociopolíticos e culturais diferentes:

1. tradição dos Estudos Culturais críticos anglo-americanos, com orientação neo-marxista e considerável influência da análise estrutural (teoria cultural francesa ${ }^{5}$ );

2. tradição Simbólica Interacionista, muito mais próxima a abordagens funcionalistas;
3. tradição dos Estudos de Consenso Cultural, com fortes raízes na Antropologia cognitiva cultural de teóricos tão diferentes como Clifford Geertz, Claude Lévi-Strauss e Victor Turner;

4. abordagens resultantes de interesses na cultura popular, movimentos populares, mídia do povo, democratização da comunicação e pesquisa sobre mídia e desenvolvimento das culturas nacionais.

Essa última tradição muda o foco segundo o qual a mídia é exclusivamente agente e fonte de construção do significado, deixando para trás a mídia como mero texto e leitura de textos e prioriza o enfoque da construção do significado por comunidades interpretativas.

Destaca a maneira como estas comunidades tomam alguns dos elementos significativos da mídia para construir sua cultura. Isto é, o estudo começa pela análise do significado que grupos particulares, informais fazem de uma determinada situação, mediante cadeias de interação social ou outros tipos de interpretação comunitária. Assim, as pesquisas enfocam áreas e processos de negociação - uma espécie de espaço constituído por agressão, resistência, sedução, boicote, debate e cumplicidade - entre a lógica da produção e a hegemonia, de um lado, e a lógica do consumo e construção da identidade na vida cotidiana, do outro.

O pesquisador Jesús Martín-Barbero refere-se a este espaço de construção negociada de significados como uma área de $z o-$

5. As principais influências são dos autores: BOURDIEU, Pierre, PASSERON, Jean-Claude. A reprodução: elementos para uma teoria do sistema de ensino. Rio de Janeiro: Francisco Alves, 1975. 238p. Distinction: a social critique of the judgement of taste (Distinção: uma crítica social ao julgamento do gosto). Cambridge: Harvard University Press, 1979. FOUCAULT, Michel. Vigiar e punir: nascimento da prisão. 7.ed. Petrópolis: Vozes, 1989. 277p. CERTEAU, Michel de. A invenção do cotidiano. Artes de fazer. Petrópolis: Vozes, 1994. 351p. BAUDRILLARD, Jean. Simulacros e simulação. Lisboa: Relógio D’Água, 1991. Selected writings (Textos selecionados). Cambridge: Polity Press, 1988. 
na de mediações ${ }^{6}$. Na sua atividade interpretativa, os grupos sociais podem tomar um dado texto da mídia como ponto de partida, mas eles criam de fato outro texto. Os textos criados vão sendo retrabalhados no decorrer dos processos históricos e culturais, os quais vão dando outros sentidos às situações vividas. Esta ênfase nas mediações incorpora muitos dos aspectos das outras três abordagens e evita enfocar exclusivamente um único agente no processo de mediação, seja o texto do meio de comunicação, seja a tecnologia (canal), seja o receptor, por exemplo. Em lugar disso, conduz todos os atores do processo de comunicação a uma dinâmica de interações e enfoca a mudança contínua de definição da situação que todos estão constantemente criando e recriando.

\section{ABORDAGEM ANGLO-AMERICANA DOS ESTUDOS CRÍTICOS CULTURAIS?}

A tradição dos Estudos Culturais britânicos é um ponto de partida importante, porque virtualmente todas as formas da Teoria da Interpretação têm alguma dívida intelectual com estudiosos como Raymond Williams, E. P. Thompson e Richard Hoggart.

Williams foi um dos primeiros a não se referir aos meios de comunicação como meras formas de transporte de informação, mas como textos que revelam significados culturais criados em um dado período histórico $^{8}$. Isso deu novos contornos às questõeschave: se a mídia provoca um impacto com- portamental objetivo, externo e definido por intenções persuasivas ou por sistemas teóri$\cos$ subjetivos de interpretação de significado. Também está implícita a perspectiva de que o significado que a mídia veicula não é criado por alguma fonte de mensagem invisível, mas por pessoas envolvidas no debate público sobre as orientações históricas de uma cultura. Williams é especialista em crítica teatral e literária e trouxe para a Teoria da Interpretação de Audiência uma série de metodologias analíticas da tradição humanista, que constituem os fundamentos dos métodos qualitativos desta teoria. Aqui se incluem a interpretação textual hermenêutica, que tenta compreender o significado de um texto no que se refere aos contextos sociocultural e histórico tanto do leitor quanto do escritor; a capacidade dos leitores de retrabalhar o significado do texto conforme seu contexto peculiar; e a constante preocupação com a problemática da resistência popular às forças ideológicas e hegemônicas.

Os estudos de E. P. Thompson e Richard Hoggart ${ }^{9}$ sobre a cultura da classe trabalhadora foram de igual modo importantes. Esta cultura é apresentada de dentro, isto é, interpretada pela própria classe trabalhadora, apresentada não como um grupo passivamente explorado, mas como um conjunto de pessoas que criam sua própria tradição paralela, a despeito da modernização da mídia de massa e da incorporação à cultura massificada. Thompson e Hoggart observaram a maneira como as classes trabalhadoras, ao se alfabetizarem, retrabalhavam textos escritos ou apresentavam-nos de

6. MARTÍN-BARBERO, Jesús, MUÑOZ, Sonia (eds.). Televisión y melodrama: géneros y lecturas de la telenovela en Colombia (Televisão e melodrama: gêneros e leituras da telenovela na Colômbia). Bogotá: Tercer Mundo Editores, 1992.

7. TURNER, Graeme. British cultural studies: an introduction (Estudos culturais britânicos: uma introdução). Londres: Routledge, 1990.

8. WILLIAMS, Raymond. Cultura e sociedade de 1780 a 1950. São Paulo: Nacional, 1969. 355p.

9. HOGGART, Richard. The uses of literacy (Os usos da cultura). Harmondsworth: Penguin Books, 1957. 
outras formas para expressar seus próprios contextos culturais e aspirações. Eles abriram, também, a discussão sobre como os textos e os significados produzidos pelas classes trabalhadoras poderiam, posteriormente, ser cooptados e transformados pelos meios de comunicação em mecanismos capitalistas de marketing de massa e em acumulações massivas de lucro.

Williams, Thompson e Hoggart definiram, logo de início, a questão-chave para a Teoria Crítica de Interpretação da mídia ao colocarem como problemática para os pesquisadores as seguintes questões: como as classes subalternas podem contestar, subverter, transformar e, dessa forma, liberar-se das leituras dominantes decodificadas nas mensagens da mídia? Responder a essas questões exige que a mídia seja analisada como poder social e processo de luta política.

Hoggart foi o primeiro a dirigir uma instituição que se tornou a maior propagadora de temas e metodologias da Teoria da Interpretação Crítica, o Centro para Estudos de Cultura Contemporânea (CECC), em Birmingham. Ele orientou as pesquisas do Centro para estudar como diferentes culturas usam a mídia e outros textos simbólicos para representar a interpretação que fazem de sua situação. Mas foi Stuart Hall quem enfrentou mais diretamente a necessidade de uma explicação intelectual aceitável para o paradoxo: em sociedades liberais e democráticas, a classe trabalhadora parece ser livre para protestar e produzir sua própria cultura antagônica, mas, ao mesmo tempo, ela permanece impotente na conformação da cultura dominante e da história política de um país.

Para Stuart Hall, diretor do CECC de 1968 a 1979, e para outros pesquisadores de alguma forma vinculados ao CECC, três questões tornaram-se centrais à pesquisa $\mathrm{em}$ comunicação:

1. Como aliados poderosos de sociedades capitalistas, como a inglesa, formados por instituições que buscam a formação de consenso no campo democrático, ainda conseguiam manter controle ideológico e ganhar o aparente consentimento de grupos das classes subalternas à sua ideologia?

2. Como poderia ser verdade que instituições da mídia sejam, ao mesmo tempo, livres de coerção direta e, ainda assim, por sua própria escolha, articulem-se sistematicamente em torno de definições que favoreçam o poder hegemônico?

3. Como os significados das práticas contestatórias culturais no âmbito da vestimenta, da música e da linguagem - por exemplo, black is beautiful (negro é lindo) -, utilizadas por movimentos de jovens das classes trabalhadoras, mulheres e minorias raciais, podem ajudar a contestar ideologias dominantes e levar a uma justiça cultural?

Subjacente a essa linha de pesquisa, permanecia um questionamento mais profundo feito pela teoria cultural marxista de classes, argumentando que modificações na base das instituições econômicas e das relações sociais de poder produziriam, automaticamente, mudanças na superestrutura cultural. Na prática, os movimentos de minorias preocupavam-se não só com os empregos e as políticas de investimentos, mas também com as políticas de símbolos culturais de identificação racial ou de gêneros de linguagem, as quais legitimam cultural e politicamente o poder social sobre os grupos subordinados. Em resumo, o que os pesquisadores do CECC tentavam mostrar é que os significados culturais e as ideologias constituíam, em si mesmos, um espaço relativamente autônomo de luta política. 
Fundamental à análise estruturalista da cultura é o princípio de que as palavras e a gramática de uma língua não são simplesmente uma reprodução objetiva de elementos e fatos do mundo real, mas sim construções sociais relativamente selecionadas. Uma premissa crucial da tradição crítica é a afirmação de que certa visão de mundo, manifesta por tais construções sociais, quando vem dos grupos dominantes, ganha credibilidade, legitima-se e é tomada como certa, enquanto outras interpretações da realidade que partem de grupos menos poderosos são desvalorizadas ou descartadas.

Esta concepção de ideologia dominante ou de leitura preferencial construída na mídia é central para a Teoria de Recepção Crítica, mas também cria um dilema. Por um lado, estudiosos progressistas, assim como Hall, têm estado preocupados com a questão de como se permite que ideologias exploradoras existam e, além disso, recebam aceitação; por outro lado, procuram também explicar como tais ideologias podem ser subvertidas e destronadas.

O CECC e Stuart Hall tomaram de empréstimo concepções teóricas da lingüística, semiótica e estruturalismo para explicar como as práticas significativas da linguagem e a formação das visões de mundo poderiam tornar-se uma arena para lutas de classe. Hall sugeriu o trabalho com três características básicas de significados, que capacitariam os oprimidos a se liberarem das leituras dominantes preferenciais:

1. o insight (compreensão) de Bakthin ${ }^{10}$, segundo o qual a natureza polissêmica da linguagem permite que a mesma palavra tenha múltiplos sentidos e, assim, significados livres latentes na tradição cultural são sempre trazidos à luz pela consciência da importância da linguagem;

2. o fato de que os significados tendem a derivar de seu contexto mítico mais amplo, um caráter unívoco natural, sagrado, rígido e de que a língua deveria ser mais relativizada por meio de processos de desmitificação e de relativização do significado das palavras;

3. as ideologias dominantes estão presentes, especialmente, nos significados conotativos e associativos das palavras, e é mais fácil mudar o sentido conotativo, por exemplo, associando a palavra black (negro) ao adjetivo beautiful (lindo).

Hall explicava, de maneira simples, práticas antigas de movimentos como o de camponeses mexicanos, que transformaram o significado pejorativo de camponês, índio e rural atribuindo-lhes a imagem de heróis da nação. Tentava demonstrar a falácia do conceito de mídia poderosa, forte argumento ideológico então sustentado pelos estudos de mídia.

\section{INTERPRETAÇÃO DE AUDIÊNCIA ATIVA}

Por volta de meados dos anos 70, a tradição dos Estudos Culturais desenvolveu um forte e razoavelmente coerente corpo de explicações teóricas do papel da mídia de massa no desenvolvimento de ideologias e manifestações culturais dissidentes, mas a explicação das supostas atividades interpretativas da audiência ainda era incipiente. David Morley ${ }^{11}$ centrou o desenvolvimento

10. BAKTHIN, M. Marxismo e filosofia da linguagem. 4.ed. São Paulo: Hucitec, 1988. 196p.

11. MORLEY, David. Television, audiences and cultural studies (Televisão, audiência e estudos culturais). London: Routledge, 1992. MOORES, Shaun. Interpreting audiences: the ethnography of media consumption (Interpretando as audiências: a etnografia do consumo da mídia). London: Sage Publications, 1993. 


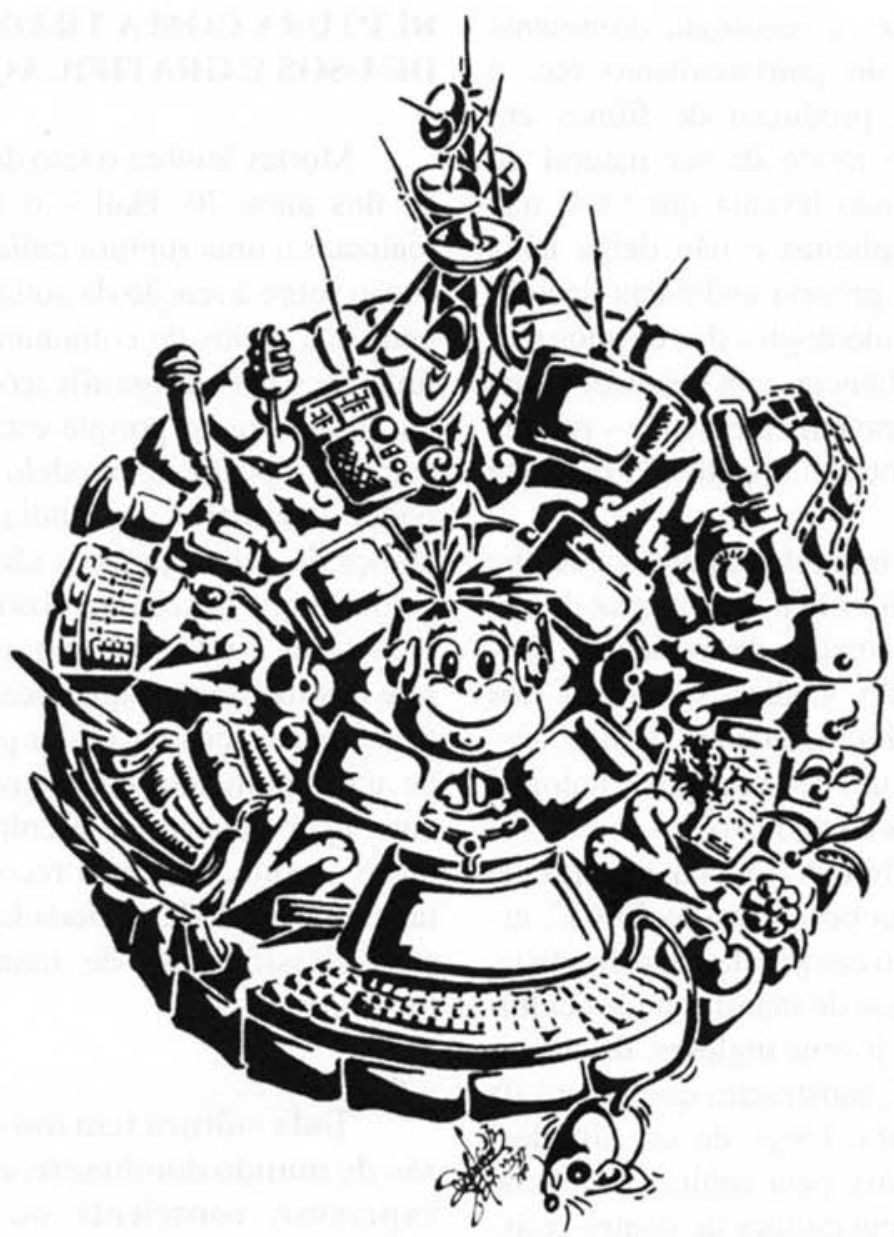

da Teoria de Audiência sob a perspectiva da crítica cultural. Seu livro não só resume o desenvolvimento de seus próprios pontos de vista, mas também fornece um dos resumos mais inteligíveis do atual debate sobre temas da pesquisa de recepção.

Morley foi o primeiro a desafiar as explicações psicanalíticas sobre as definições ideológicas de respostas dadas pela audiência, propostas pelos teóricos franceses Lacan e Althusser e adotados pela Escola Teórica do Cinema, representada pela revista inglesa Screen (Tela).
De acordo com este ponto de vista, na cultura de um sistema capitalista industrial os processos de socialização, que se dão na família e na escola, desenvolvem os gostos e as percepções da audiência e também estão na lógica dos filmes populares de massa e na programação de televisão, portanto, são dois lados da mesma moeda. Ou seja, o sistema impõe sua ideologia ao determinar como a personalidade infantil se desenvolverá por meio de práticas normalmente aceitas na educação e também determinará o modo que um filme irá dirigir-se (interpelar) e canalizar as reações da audiência para conclusões ideológicas já esperadas. 
Por exemplo, a ideologia dominante do capitalismo, do patriarcalismo etc. é apresentada pela produção de filmes em Hollywood como modo de ser natural do mundo. $\mathrm{O}$ texto não levanta questões, não deixa críticas implícitas e não deixa nada em aberto para a própria audiência decidir. Dada a definição ideológica dos desejos psicanalíticos da audiência, esta forma de filme realista - não surpreendentemente - produz muito prazer e entretenimento e é bastante popular.

Seguindo este modelo, pensava-se que muito da pesquisa crítica seria capaz de explicar o comportamento da audiência simplesmente fazendo análise semiótica dos conteúdos da mídia, deduzindo, assim, desses conteúdos tanto as intenções autorais como as respostas da audiência.

Morley, refletindo o pensamento de Stuart Hall12 e das pesquisas do CECC, argumentou que isso era por demais simplista. Os diversos estudos de manifestações culturais de grupos de jovens ingleses, desenvolvidos pelo $\mathrm{CECC}$, mostraram que jovens da classe trabalhadora, longe de ser simplesmente manipulados pela mídia de massa, desenvolveram uma cultura de contra-resistência e resistência ou um discurso que os capacitava a interpretar a mídia de massa de acordo com a leitura preferencial dominante, mas também de variadas formas em oposição ao estabelecido. $\mathrm{O}$ texto é muito mais polissêmico e aberto a várias interpretações do que se tinha suposto. É necessário analisar as culturas a fim de ver como grupos diferentes, em diversos contextos socioeconômicos, desenvolvem diferentes conjuntos de códigos e de discursos de interpretação da cultura de massa.

\section{RUPTURA COMA TRADIÇÃO DE USOS E GRATIFICAÇỐES}

Morley lembra o fato de que, no começo dos anos 70, Hall e o CECC também realizaram uma ruptura radical com a explicação sobre a reação da audiência às mensagens dos meios de comunicação a partir da linha dos usos e gratificações. Isso se deu em grande parte porque esta teoria fica no extremo oposto ao modelo que destaca o poder ideológico da mídia e resultou na crença de que as pessoas são livres para escolher o que desejarem absorver da mídia e para fazer a interpretação que bem desejarem das mensagens que recebem. Conquanto as mensagens da mídia possam ter mais de um significado conotativo e as audiências sejam capazes de escolher entre um ou outro sentido, devemos reconhecer que potencialmente toda sociedade tende a impor suas classificações de mundo sobre seus membros.

Toda cultura tem um ethos e uma visão de mundo dominante, $\mathrm{e}$ isso tende a se expressar, consciente ou inconscientemente, na leitura preferencial codificada pela mídia. A fórmula clássica ensina que as audiências são livres para selecionar, porém em determinadas situações que não são de sua própria escolha. O consumo de conteúdos veiculados pela mídia é determinado mais pela disponibilidade, pela oferta de programação do que pela seleção que as pessoas provavelmente gostariam de fazer. As audiências tendem a definir suas preferências de acordo com o que está disponível.

12. HALL, Stuart. The rediscovery of 'ideology': return of the repressed in media studies (A redescoberta da 'ideologia': o retorno dos reprimidos nos estudos de mídia). In: GUREVITCH, Michael et al. (eds.). Culture, society and media (Cultura, sociedade e mídia). London: Routledge, 1982. p.56-90. HALL, Stuart et al (eds.). Culture, media, language (Cultura, midia, linguagem). London: Hutchinson University Library, 1980. 
A pesquisa com base em usos e gratificações tende a enfocar exclusivamente os estados psicológicos dos indivíduos, os quais são determinados pelas necessidades internas de organização da personalidade de cada um. Há uma tendência para se abstrair tanto o contexto social das diferentes culturas como os discursos que dão forma às escolhas. Esta teoria dos usos e gratificações, segundo Morley, encara a audiência como uma massa atomizada e está mais de acordo com as teorias iniciais de estímuloresposta. Presume, também, uma interpretação individual, particular dos produtos veiculados pelos meios de comunicação. Morley argumenta que precisamos encarar as leituras da mídia como parte de um processo social e de movimentos culturais que englobam os indivíduos em uma esfera cultural mais ampla.

\section{AUDIÊNCIAS E LEITURA PREFERENCIAL}

Entre 1975 e 1979, David Morley e Charlote Brunsdon ${ }^{13}$ tentaram testar empiricamente as teses do CECC, segundo as quais a posição da classe social e os interesses políticos influenciam a maneira que os telespectadores decodificam um dado programa de televisão. Queriam estabelecer um caminho entre duas teorias psicológicas: a dos textos ideológicos, determinando as respostas da audiência, e a de que os indivíduos são livres para formular suas respostas à mídia. Numa tentativa de não tratar a audiência como uma massa de indivíduos indiferenciados, Morley e Brunsdon adaptaram a análise da audiência à teoria sociológica de Frank Parkin, segundo a qual a sociedade se divide em classes sociais determinadas e os membros de tais classes habitam um sistema de significado ou uma estrutura ideológica ${ }^{14}$.

Parkin argumentou que podemos distinguir três sistemas de significado mais abrangentes, cada um promovendo uma interpretação moral diferente da desigualdade social:

1. o sistema de valores dominantes promove o endosso da desigualdade de classes sociais existente, estabelecendo variados termos de acordo social, especialmente entre os que claramente são beneficiados a partir dessa desigualdade;

2. o sistema de valores dos subordinados, fonte social ou meio gerador do qual procede a comunidade da classe trabalhadora local, é uma estrutura que promove uma resposta que forçosamente se acomoda aos fatos da desigualdade social e da falta de status;

3. o sistema de valores radical, fonte em que se baseia o partido político das massas, fundamentalmente constituído pela classe trabalhadora, é uma estrutura que promove a interpretação de oposição às desigualdades de classes.

Morley e Brunsdon, como a maioria dos analistas críticos da mídia de sua época, adaptaram suas explicações do poder da estrutura social e da ideologia assumindo, pelo menos implicitamente, que a leitura preferencial, que organiza o material polissêmico do programa em torno de uma mensagem central, refletiria o sistema de valores dominantes, sustentando as desigualdades de classe.

13. BRUNSDON, Charlote, MORLEY, David. Everyday television: Nationwide (Televisão do dia-a-dia: De âmbito nacional). London: British Film Institute, 1978.

14. PARKIN, F. Class inequality and political order (Desigualdade social e ordem política). London: Paladin, 1971. 
Desta estrutura sociológica também procedeu a afirmação de que as audiências são tipicamente divididas em níveis de gerenciamento, fazendo acordos com a ideologia dominante, em geral realizados entre aqueles elementos da classe trabalhadora que fariam interpretações negociadas e aqueles que, identificados com os movimentos sociais, buscando transformar a sociedade, realizariam interpretações de oposição.

O estudo de Morley examinou respostas apresentadas em um programa vespertino de variedades que mostrava casos comuns do dia-a-dia, uma espécie de talk-show, o Nationwide (De âmbito nacional), apontado como o mais acrítico com relação às ideologias dominantes. $\mathrm{O}$ estudo destacava, então, trechos do programa para grupos selecionados de receptores, os quais representavam segmentos de classes sociais significativos gerentes de banco, dirigentes sindicais, vendedores de loja, estudantes universitários de arte, estudantes universitários negros, estagiários e estudantes e aprendizes do magistério - e estabelecia uma discussão estruturada para explicitar opiniões a favor ou contra o conteúdo dos programas.

A análise dos resultados mostrou que o processo de interpretação de audiência era muito mais complexo do que o modelo codificar-decodificar sugeria. Apesar de as diferenças de status dentro do grupo tenderem a produzir acordos, negociações e oposições, ficou claro que os indivíduos estavam agindo com base em um conjunto de histórias e interpretações não manifestas e até mesmo contraditórias ${ }^{15}$. Freqüentemente não fica claro qual é a leitura preferencial a ser aprovada ou contraditada: se ela é a intenção ideológica do argumento do autor do programa ou se é o uso inconsciente de cer- tas formas tradicionais de novos gêneros em sua expressão lingüística ou, ainda, se é a leitura particular de uma análise sociológica habilidosa.

A crítica do próprio Morley a essa pesquisa e os inúmeros debates que se seguiram exerceram grande influência para a abertura de uma nova etapa na análise da relação entre os textos da mídia e as interpretações da audiência.

A principal crítica, feita pelo próprio Morley, é de que a análise deve tomar como ponto de partida não só construções de hipóteses sociológicas dos processos de decodificação da audiência, mas também observações práticas sobre a mídia, usadas dentro de seu contexto. A interpretação que um vendedor faz dos programas dos meios de comunicação, conversando com outros vendedores, pode ser bem diferente da interpretação que ele faz em sua casa, com a esposa, num ambiente familiar casual junto com parentes e vizinhos. Além disso, a discussão provocada sobre um programa de TV, normalmente não escolhido pelo receptor e visto como irrelevante por muitos, talvez não revele a real interpretação das notícias da televisão e nem mesmo as interpretações do drama ficcional.

\section{ABORDAGEM ETNOGRÁFICA DA AUDIÊNCIA}

No final dos anos 70 e início dos 80 , começou a despontar certo descontentamento com estudos que faziam inferências sobre o significado dos produtos da mídia para as audiências, baseados em questionários que levavam em conta apenas os textos da mídia. Muitos comentavam que a pesquisa deveria permitir que os membros

15. MORLEY, David. The Nationwide audience: structure and decoding (A audiência De âmbito nacional: estrutura e decodificaçāo), London: British Film Institute, 1980. 
da audiência definissem o significado dos programas a partir de sua própria estrutura interna subjetiva de referência e não a partir de construções objetivas impostas de fora por sociólogos. A tradição dos Estudos Culturais já havia dado um passo nesta direção, mas a pesquisa de campo estava ainda dominada por tais explicações hipotéticas e normativas ao invés de entrar completamente na construção subjetiva do significado, por meio de métodos etnográficos da Antropologia Cultural.

Shaun Moores ${ }^{16}$ aponta dois pioneiros na utilização de métodos de observação direta da mídia dentro do ritmo natural e sem perturbações da vida doméstica: James Lull, nos Estados Unidos, com sua pesquisa sobre interações familiares em torno de programas de televisão ${ }^{17}$ e Dorothy Hobson, na Inglaterra, com suas entrevistas e observação da utilização das interpretações a respeito da mídia, dentro das rotinas familiares ${ }^{18}$.

As pesquisas de Lull e Hobson revelaram que assistir à televisão não é uma atividade necessariamente isoladora $\mathrm{e}$ individualista, mas em muitos casos constitui fator de união familiar, propiciando momentos de diálogo.

Hobson estabeleceu, em sua pesquisa, que as esposas vivem uma existência isolada, subordinada e dominada por rotinas cotidianas intermináveis e enfadonhas do trabalho caseiro. Pensava-se que os hábitos de consumo da mídia pelas donas de casa fi- zessem parte desta dependência alienatória. $\mathrm{O}$ estudo confirmou muito disso, porém também indicou que as mulheres se identificavam com tipos particulares de mídia e isto as ajudava a reafirmar sua identidade feminina e reforçar seus desejos de liberdade. As pesquisas de Lull e Hobson sugeriram um papel positivo da mídia na vida diária das pessoas, iniciando um movimento de reavaliação dos valores de muitos gêneros execrados, como, por exemplo, o das novelas diárias a que as mulheres adoram assistir.

Por volta de meados dos anos 80 , diversos estudos de campo questionavam membros da audiência sobre o prazer e a identificação que sentiam com programas veiculados pela mídia popular de massa, entre eles podemos citar: o estudo de Hobson a respeito das interpretações subjetivas das mulheres sobre a soap opera inglesa Crossroads (Encruzilhada); o estudo de Ien Ang sobre o prazer dos que assistiam a Dallas; e as observações de Hodge e Tripp sobre as interpretações infantis da televisão australiana ${ }^{19}$.

\section{PRAZER E POPULARIDADE DA MÍDIA}

Uma das mais significativas linhas de pesquisa de interpretação de audiência é o movimento fundamentado no ponto de vista segundo o qual fazer que as classes trabalhadoras sintam prazer através da mídia é simplesmente uma estratégia para induzi-las à aquiescência política. $\mathrm{O}$ fato de $\mathrm{a}$ televisão ser tão popular tem levado os

16. MOORES, Shaun. Interpreting audiences... op. cit.

17. LULL, James. The social uses of television (A utilização social da televisão). Human Communication Research (Pesquisa sobre comunicação humana), v.6, n.3, 1980. p.198-209.

18. HOBSON, Dorothy. Housewives and the mass media (Donas de casa e a mídia). In: HALL, Stuart et al (eds.). Culture, media, language. London: Methuen, 1980. p.105-114. Crossroads: the drama of a soap opera (Encruzilhada: o drama de uma soap opera). London: Methuen, 1982.

19. ANG, Ien. Watching Dallas: soap opera and the melodramatic imagination (Assistindo Dallas: soap opera e imaginação melodramática). London: Routledge, 1991. HODGE, Bob, TRIPP, David. Los niños y la televisión (As crianças e a televisão), Barcelona: Planeta, 1988. 283p. 
pesquisadores a questionar mais seriamente por que a TV significa tanto para tanta gente. Alguns deles têm estudado o sentimento de poder e de prazer do público de assumir papéis ou de participar ludicamente de enredos, assumindo uma outra identidade ${ }^{20}$. Os telespectadores seriam, depois dessa experiência, mais capazes de avaliar objetivamente as identidades fornecidas ou impostas pela sociedade.

Muitos pesquisadores críticos da mídia defendem a postura de que os grupos subordinados se apegam ao prazer vulgar e o saboreiam como símbolo de sua independência, precisamente por ele parecer subversivo aos grupos dominantes ${ }^{21}$. Grossberg ${ }^{22}$ apontou a música rock como um símbolo assim para os jovens. Mary Ellen Brown mostra que as mulheres fãs de telenovelas diárias apegam-se precisamente ao lixo e a produções de baixa qualidade como símbolo de desafio e de solidariedade a suas parceiras $^{23}$. Martín-Barbero ${ }^{24}$ argumenta que, na América Latina, o começo da subversão política acontece com o melodrama. A subversão e a liberação estão exatamente no prazer por um gênero que é só desse grupo, cruzando fronteiras da decência primária e parodiando a racionalidade estreita daqueles que não conseguem compreender por que tal gênero é prazeroso e encaram quem assiste a ele como alienado.

\section{TESE DA AUDIÊNCIA ATIVA}

Em 1987, John Fiske ${ }^{25}$, a partir dos resultados de muitos destes estudos, apresentou em seu provocativo livro Television and culture (Televisão e cultura) uma série de teses sobre a audiência ativa. As principais delas são:

1. a audiência de massa é muito heterogênea e faz variadas interpretações de um mesmo programa;

2. as interpretações individuais sobre a televisão não são pré-determinadas, mas emergem de um histórico social complexo, de informações alternativas fornecidas pelas diferentes culturas e dos pontos de vista de oposição de redes sociais informais;

3. a polissemia da televisão - a ironia verbal/visual, a paródia, a sátira, variações contínuas, novos gêneros e comparações intertextuais óbvias - convida a respostas de resistência, alternativas e céticas por parte da audiência;

4. a televisão, a fim de apelar à pluralidade heterogênea das audiências e às culturas estrangeiras, emprega narrativas muito mais abertas.

Pelo final dos anos 80, a nova perspectiva teórica de construção ativa dos significados pela audiência e a metodologia de etnografia de audiência começavam a despontar

20. ANG, len. Watching Dallas... op. cit.

21. HEBDIGE, D. Subculture: the meaning of style (Subcultura: o significado do estilo). London: Methuen, 1983. MORLEY, David. The Nationwide audiences... op. cit. The Nationwide audience: a critical postcript (A audiência de Nationwide: um posfácio crítico). Screen Education (Educação pela tela), 1981. p.39. Television, audiences... op. cit.

22. GROSSBERG, Lawrence. Strategies of marxist cultural interpretation (Estratégia da interpretação cultural marxista). Critical studies in mass communication (Estudos críticos de comunicação de massa), v.1, n.4, 1984. p.392-421.

23. BROWN, Mary Ellen. Motley moments: soap opera, carnival, gossip and the power of the utterance and consumption and resistence - the problem (Variedades: soap opera, carnaval, bate-papos e poder da expressão oral e consumo e resistência o problema). In: (ed.). Television and women's culture: politics of the popular (Televisåo e cultura feminina: politica do povo). London: Sage Publications, 1990. p.183-210. Soap opera and women's talk: the pleasure of resistance (Soap opera e conversas entre mulheres: o prazer da resistência). Thousands Oaks, California: Sage Publications. 1994.

24. MARTÍN-BARBERO, Jesús. Dos meios às mediações: comunicação, cultura e hegemonia. Rio de Janeiro: UFRJ, 1997.

25. FISKE. John. Television and culture (Televisão e cultura). London: Routledge, 1991. 
como as maiores correntes de pesquisas de audiência. A tradição crítica marxista reagiu abrindo fogo contra estes estudos, afirmando que eles esvaziavam o conteúdo ideológico da mídia. Para muitos, a ênfase na audiência ativa é um tipo de ideologia populista do poderio da audiência. Os textos de Fiske, de 1987, foram criticados como o epítome do exagero na concessão de liberdade quase ilimitada à audiência para construir como bem desejasse o significado da programação da televisão. Morley resume bem a maioria dessas teses caricaturais sobre pesquisas de audiência ativa, as quais transformam a audiência de consumidora passiva, manipulada, em protagonista de uma guerrilha de sala-de-estar contra as ideologias dominantes. Morley busca, porém, um equilíbrio entre os dois extremos.

\section{PODER DA AUDIÊNCIA}

Uma primeira tese caricatural do ativismo da audiência é a que afirma que "qualquer que seja a mensagem codificada, a mídia dominante será fraca e ineficiente, desde que o povo estabeleça seus próprios significados e tenha prazer. Longe de ser dopado cultural, o povo não só é naturalmente crítico, colocando elementos de sua própria escolha para construir uma opinião oposicionista, mas também confere poder a si mesmo para lutar contra a tentativa das forças da ideologia político-econômica em influenciar a mídia" 26 .

Uma das evidências em favor do poder da mídia é a de que os produtores têm sido hábeis e bem-sucedidos, pois conseguem, com um gênero tão específico como o das novelas diárias femininas, atrair uma ampla gama de audiências; vender estas audiências para anunciantes; e, além disso, levar os anunciantes (comerciais, políticos ou religiosos) a descobrir que podem vender seus produtos durante o entretenimento. A mídia de massa é, fora de qualquer dúvida, uma das mais importantes agendas de negócios de nossa sociedade.

Por outro lado, um bom argumento a favor do poder da audiência atesta que para cada Dallas há dúzias de programas de TV rejeitados pelo público. Inúmeros governos ao redor do mundo, os quais tiveram controle ideológico completo sobre a mídia, foram rejeitados e caíram exatamente por causa de seus esforços para controlá-la. Virtualmente, todos os estudos de audiência que permitem aos entrevistados indicar com liberdade sua construção do significado de um programa mostram uma imensa variedade e divergência de interpretações entre os diferentes receptores e deles mesmos em diferentes momentos. Sempre é difícil determinar com precisão a leitura preferencial de um programa, mesmo nas análises semióticas mais especializadas, principalmente no que se refere ao sentido político. Certamente, há pouco consenso entre os membros da audiência sobre qualquer que seja a interpretação.

Argumentar, porém, que as leituras divergentes automaticamente impliquem que o povo rotineiramente desenvolve leituras opostas à clara mensagem denotativa preferencial da mídia é muito questionável. Mais improvável ainda é que as pessoas facilmente mudem sentimentos de dúvida ou de forte oposição para uma atitude política mais evidente.

Morley sugere que Fiske fez generalizações precipitadas a partir de estudos de grupos isolados de culturas claramente 
oposicionistas, tais como as interpretações que aborígines australianos fazem da programação de TV gerida pelos grupos dominantes nacionais ou importada do Ocidente.

Há evidências de que, sob certas circunstâncias políticas, alguns meios de comunicação podem se nutrir do emocionalismo e dos símbolos públicos de movimentos populares de oposição. Por exemplo, certos tipos de rock e eventos musicais, como o Woodstock, foram catalisadores simbólicos dos movimentos políticos de contracultura do final dos anos 60 e começo dos anos 70 , especialmente do movimento jovem contra a guerra do Vietnã 27 . Porém, o conjunto complexo de fatores, tal como a produção de um discurso de oposição capaz de captar e de traduzir o significado dos símbolos públicos, a partir de uma linguagem de discursos privados ou semiprivados, precisa ser cuidadosamente estudado.

É neste sentido que Mary Ellen Brown argumenta que a novela diária, um gênero para mulheres, gera um discurso de oposição. Porém, ele é construído a partir de redes internas de bate-papos entre mulheres, dentro de uma estrutura familiar fortemente patriarcal.

\section{EM DIREÇÃO A UMA SEMIÓTICA DEMOCRÁTICA}

Fiske argumenta que a maior parte dos produtores de TV, especialmente os que objetivam atingir audiências de massa ou audiências potencialmente tipo exportação, tentam criar textos mais abertos a interpretações diversas ${ }^{28}$. Esses textos não só são construídos de forma mais aberta, com metáforas conotativas, ironia, duplo senti- do, subenredos e personagens ambíguos que permitem ampla gama de interpretações, como também seus significados estendem-se para além do programa em si, abrangendo reportagens em revistas para fãs de TV, artigos plantados em jornais sobre os participantes do elenco de novelas, bem como comentários encomendados a críticos. O texto é construído de maneira a convidar a audiência a entrar no script, atuando em conjunto e reestruturando o enredo de tais programas populares em discussões que acontecem durante e após sua produção. $\mathrm{O}$ envolvimento da audiência, tipicamente representado pelos clubes de fãs, é a base do prazer da audiência e do sucesso de um programa. A audiência precisa sentir-se participante do programa e promovê-lo entre amigos e vizinhos. Fiske evoca Roland Barthes ao indicar que um texto tem significado e ganha sentido somente quando é lido pelo seu público. Fiske parece trazer para a discussão o conceito de leitura preferencial.

Morley sugere que Fiske se tornou tão obcecado pela idéia de rejeitar o argumento do texto fechado, que esquece que os textos existem dentro de um sistema hegemônico. Recebem anuência do sistema, não diretamente, mas por meio de muitos elementos indiretos, que limitam a negociação; sendo aparentemente abertos, acabam, no entanto, como reprodutores do sistema. Fiske recentemente tem usado a análise cultural francesa de Michel de Certeau ${ }^{29}$ para argumentar que as pessoas usam a tática de enfraquecimento para desmanchar pedaços e porções dos significados estabelecidos e criar, à margem do sistema cultural, suas próprias construções de significado.

27. MARTíN, Berenice. The sociology of contemporany cultural change (A sociologia da mudança cultural contemporânea). New York: St. Martin's Press, 1981.

28. FISKE, J. Television... op. cit.

29. CERTEAU, Michel de. A invenção do cotidiano... op. cit. 


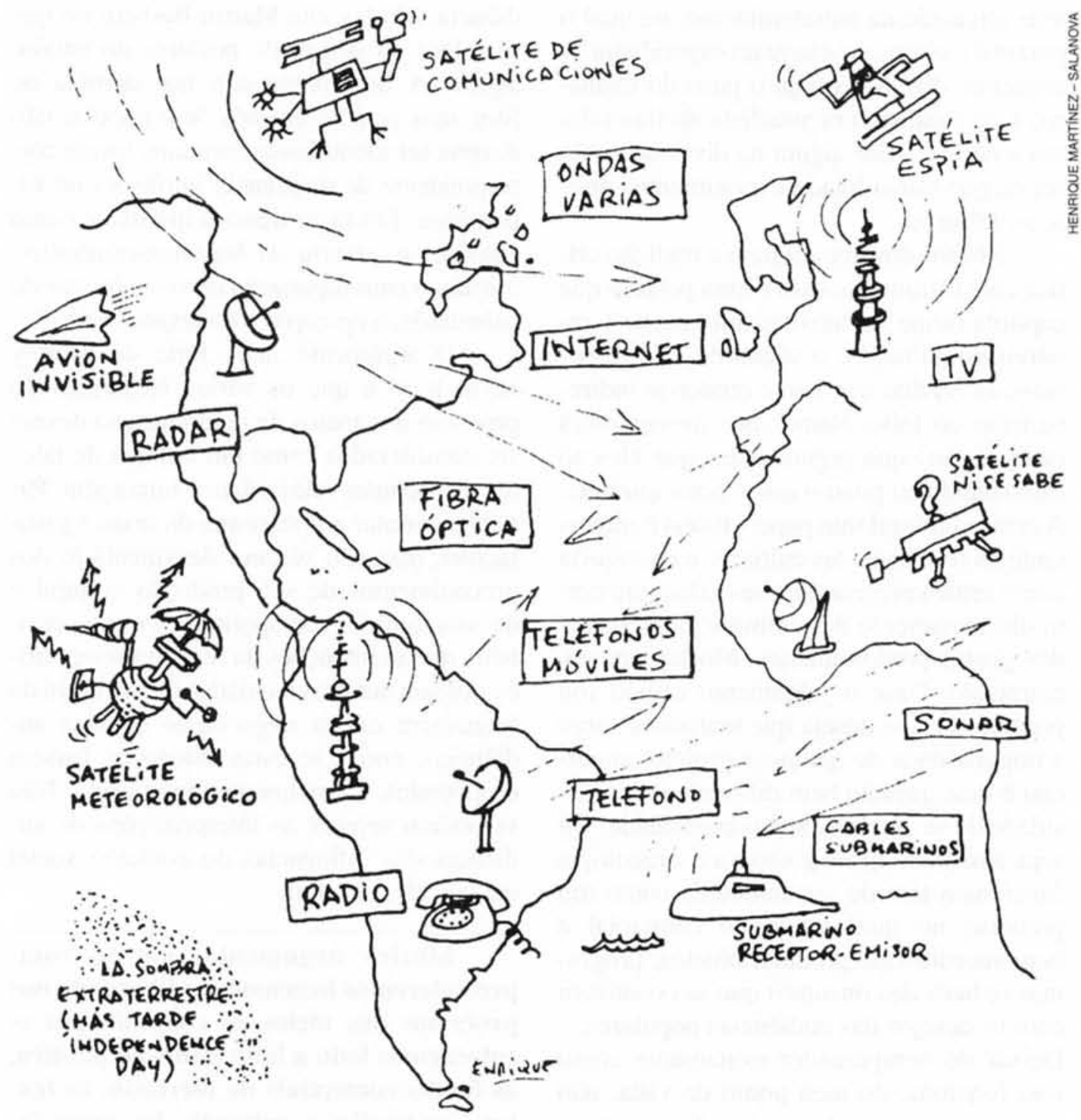

\section{CELEBRAÇÃO ACRÍTICA DA CULTURA POPULAR}

Uma reação ao tipo de análise dispensado à massa e à mídia popular por estudiosos da Escola de Frankfurt, como Adorno e Horkheimer ou por aqueles que vêem com pessimismo e negativismo qualquer mídia de massa, tem sido representada pela celebração da cultura popular massiva como uma forma de respeito aos pobres e à classe trabalhadora. Para esses pesquisadores, os gostos das camadas populares não são necessariamente piores, apenas diferentes, dados os seus contextos culturais de vida diferenciados. Se a massa popular acha divertido assistir à novela ou ao gênero seriado de aventuras, então tem direito de ter sua própria cultura. Essa linha de pensamento defende que a mídia é um momento de lazer, 
uma atividade de entretenimento, na qual o prazer é o elemento-chave na experiência. A esquerda, dizem, carrega o peso do dualismo e do legalismo racionalista do Iluminismo e não vê valor algum na diversão a não ser na que esteja ligada a movimentos políticos utópicos.

Muitos dos que seguem a tradição crítica consideram que essa é uma postura que capitula frente ao consumismo, aceita o relativismo cultural e o vácuo de valores sociais. Já foi dito que isso é render-se indiretamente ao falso clamor dos deregulators (sem regras) que argumentam que eles só estão dando ao povo o que o povo quer etc. A crítica cultural tem papel crucial e importante na formação das culturas, e a pesquisa como crítica precisa sempre manter um certo distanciamento das culturas industriais e dos gostos predominantes. Morley aponta, entretanto, "que o julgamento crítico (ou político) que se deseja que tenhamos sobre a popularidade de qualquer projeto comercial é uma questão bem diferente da necessidade de se entender sua popularidade. $\mathrm{Ou}$ seja, a maneira que o gosto e até a ideologia funcionam tem de ser entendida como um processo no qual o mundo comercial é bem-sucedido em produzir objetos, programas (e bens de consumo) que se coadunam com os desejos das audiências populares... Deixar de compreender exatamente como isso funciona, do meu ponto de vista, não só é academicamente retrógrado, mas também suicídio político" ${ }^{30}$, diz Morley.

\section{REUNIR O TEXTO, O LEITOR E O CONTEXTO}

Ao sintetizar estes debates sobre a natureza ambígua das interpretações de au- diência, Morley cita Martín-Barbero no que se refere ao perigo de posturas do isto/ou aquilo. A hegemonia não nos domina de fora, mas penetra em nós "e o popular não deveria ser identificado com uma forma correspondente de resistência intrínseca ou espontânea. Em lugar disso, a questão é como entender a 'textura da hegemonia/subalternidade, o entrelaçamento da resistência e da submissão, a oposição e a cumplicidade" "'31.

$\mathrm{O}$ argumento mais forte de Morley nesse livro é que os vários elementos do processo dos meios de comunicação devem ser considerados como um sistema de fatores que se inter-relacionam e interagem. $\mathrm{Pa}-$ ra ele, apontar a polissemia do texto é justificável, mas não se deve desvinculá-lo dos procedimentos de sua produção cultural e de sua função sociopolítica. Pensar, também, que as intenções da função sociopolítica possam ser desvinculadas da estrutura da linguagem ou da negociação com as audiências, como se estas intenções fossem onipotentes, é igualmente uma falácia. Não se podem separar as interpretações de audiência das influências do contexto social em que elas ocorrem.

Morley argumenta que só compreenderemos hegemonia e liberdade nos processos dos meios de comunicação se colocarmos lado a lado a função política, as forças comerciais de mercado, os textos e as tradições culturais das quais fazem parte as tecnologias, as audiências e seu prazer, o nível microssocial do lar e o macrossocial do sistema social, bem como outros fatores num conjunto de inter-relações, todos revelando simultaneamente resistência e submissão, oposição e cumplicidade. 
Morley indica diversas tradições em pesquisa de comunicação que constituem, particularmente, janelas úteis para que se compreenda o processo de negociação que se dá na constituição da hegemonia da mídia: o estudo de gêneros da mídia, o contexto doméstico do uso da mídia e a maneira que as novas tecnologias da mídia são introduzidas no ritmo da vida diária, no cotidiano.

\section{NEGOCIAÇÃO ENTRE HEGEMONIA E AUDIÊNCIAS}

Por várias razões, Morley sugere que a melhor estrutura para interpretar pesquisas de audiência é a dos gêneros da mídia, porque a teoria dos gêneros direciona a pesquisa para as verdadeiras práticas de produção e de utilização da mídia.

Gêneros como novela, tipos de música popular, esportes, certos noticiários etc. são textos negociados, que representam uma intersecção entre os sempre contraditórios discursos, não podendo ser simplesmente reduzidos a um suporte de classe, raça ou subordinação de gênero. Por exemplo, a novela feminina diária incorpora alguns discursos contestatórios, antipatriarcais para que as mulheres se identifiquem. Mas, ao mesmo tempo, a novela vende produtos domésticos sugerindo que o lugar da mulher é em casa, como fiel serva do marido e da família. Como indicam muitos dos estudos de audiência de novelas, um dos aspectos do texto mais apreciados é a apresentação contraditória e irônica do sentimentalismo: tão emocionalmente envolventes, mas ao mesmo tempo tão exagerados que evocam risos na audiência e um sentimento de piedade/poder sobre o sofrimento da heroína.

A teoria do gênero encara os programas não como simples doutrinação política, mas como arte popular e entretenimento. Ao examinar como alguns gêneros cons- truíram uma relação com suas audiências, é possível ir além da análise artificial audiência-programa, que destaca apenas aquilo que se refere à aceitação ou rejeição de ideologias, e avançar para estudos sobre como os programas se relacionam com as competências culturais (condição de compreensão), os interesses (relevância) e as identidades culturais. $\mathrm{O}$ pesquisador deve, antes de mais nada, perguntar aos produtores quais as competências culturais que eles pressupõem para suas audiências e como eles almejam que um programa se engaje naquelas competências culturais. Assim, a pesquisa volta-se para a compreensão que a audiência tem de sua competência cultural. Por exemplo, mulheres que acompanham novelas ridicularizam a incapacidade dos homens para entender e apreciar os enredos intrincados. Adolescentes adoram o fato de seus pais ou mesmo seus irmãos mais velhos não entenderem os estilos de música popular mais modernos.

Os gêneros tendem a endereçar-se a grupos particulares - mulheres, homens, jovens, crianças, idosos etc. - sendo usufruídos em seu contexto natural de consumo de mídia (casa, tempo de lazer), em estados de espírito particulares e em redes coletivas de significações (nas conversas para colher a opinião de outras mulheres, de seus pares etc.).

A maioria dos apreciadores dos gêneros são parte do público ou fãs que escolheram tal programa ou gênero por terem adquirido considerável senso crítico para fazer a escolha de suas produções favoritas, para conhecer a qualidade de atuação de seus atores preferidos etc. Este público está sempre consciente de sua luta contra elementos ideológicos característicos.

Os gêneros têm regras particulares para a construção de significados no âmbito da produção de decisões, sendo a negociação 
do conteúdo ideológico mais visível e aberta a análise. Cada gênero representa um tipo particular de negociação ideológica num momento histórico específico.

\section{POLÍTICA DO USO DA MÍDIA EM CASA}

Depois de seu trabalho crítico com o estudo Nationwide (De âmbito nacional) ${ }^{32}$, Morley direcionou sua pesquisa para o estudo da apreciação da mídia em seu contexto mais típico: a família e o ambiente doméstico. Um dos principais objetivos de Morley é preservar a linha de análise crítica com base no poder e na ideologia na mídia e integrar a ela o novo estudo etnográfico da mídia, no contexto de sua execução prática.

Essa pesquisa revelou uma briga na família entre maridos e mulheres, pais e filhos sobre as escolhas de programação efetuadas e sobre as interpretações dos significados de seu conteúdo. De várias formas, a família constitui um microcosmo das lutas pelo poder cultural e social que acontecem no âmbito da sociedade. Os elementos não são sociológicos e abstratos, mas muito concretos, evidenciando a subordinação de mulheres às demandas patriarcais de maridos e de jovens com novos ideais em relação a uma geração mais velha, bem como os debates sobre opções políticas e escolha de identidade étnica/religiosa.
A mídia é a janela entre o microcosmo, onde se trava a luta entre decisões pessoais e escolhas de identidade num contexto familiar, e os movimentos nacionais/internacionais que servem como pontos de referência para estas mesmas identidades.

As pesquisas críticas da mídia reconhecem agora que as estruturas constroem-se sobre práticas do cotidiano e, assim, estas pesquisas voltam-se para teorias de formação cultural na vida diária, tais como as propostas por Pierre Bourdieu e Michel de Certeau ${ }^{33}$.

Morley identifica-se com Giddens, Gledhill ${ }^{34}$ e outros que substituiriam o termo hegemonia negociada (uma mudança contínua, processo instável) por dominação ideológica (um estável, estabelecido e garantido efeito). A estrutura societária do poder é constituída por miríades de lutas para definições de identidade e de cultura acontecendo nos lares, nas associações de amigos, grupos de jovens, nas organizações, como a Igreja, e nas instituições de produção musical.

$\mathrm{O}$ estudo de Andrea Press ${ }^{35}$ a respeito da percepção feminina sobre a soap opera Dinastia sustenta o ponto de vista segundo o qual a televisão exerce controle hegemônico sobre os telespectadores de um modo muito variado e paradoxal. Em alguns momentos, as mulheres resistem ao ponto de vista hegemônico e, em outros, o aceitam. Por exemplo, mulheres da classe trabalha-

32. MORLEY, David. The Nationwide audiences... op. cit.

33. BOURDIEU, Pierre, PASSERON, Jean-Claude, A reprodução... op, cit. CERTEAU, Michel de. A invenção do cotidiano... op. cit.

34. GIDDENS, Anthony. Central problems in sociological theory (Problemas centrais na teoria sociológica). London: Hutchinson, 1979. GLEDHILL, C. Pleasure negociations (Negociaçōes agradáveis), In: PRIBRAM, E. Female spectators (Espectadoras femininas). London: Verso, 1988.

35. PRESS, Andrea. Women watching television: gender, class and generation in the American television experience (MuIheres que assistem à televisão: gênero, classe e geração na experiência televisiva norte-americana). Philadelphia: University of Pennsylvania Press, 1991. 238p. 
dora que rejeitavam uma identificação com papéis femininos de Dinastia tendiam a aceitar valores, atitudes e cosmovisões ali apresentadas como um bom retrato do mundo. Mulheres de classe média com atitude negativa e de resistência com relação à televisão identificavam-se, ainda assim, com os papéis femininos de Dinastia.

\section{INTERAÇÃO SOCIAL E DISCURSO DE REDES DE AUDIÊNCIA ${ }^{36}$}

Recentes pesquisas críticas sobre audiência reforçam as observações de Morley de que a dimensão política deve ser esclarecida no contexto social da apreciação da mídia. Publicações recentes de Mary Ellen Brown argumentam que a visão segundo a qual a televisão despolitiza ou controla a orientação política da audiência está freqüentemente baseada na asserção de que as audiências interpretam a mídia de forma pessoal e isolada.

O estudo etnográfico de Brown sobre conversas entre mulheres a respeito de novelas mostra que elas encaram seu gênero favorito como parte de uma rede de discursos e o significado deles permanece indefinido até que sejam discutidos e debatidos com outras mulheres que também acompanham a novela.
Esta discussão aviva a identidade cultural das mulheres (seus sentimentos expressos em conversas, reclamações da vida em famílias patriarcais etc., com outras mulheres), com informações que só os que acompanham novelas têm e com dados de como as mulheres encaram o mundo em geral. As novelas exercem atração sobre as mulheres por terem um estilo de discurso parecido com a maneira como elas se comunicam entre si. Mantêm o interesse delas abordando temas e modelos de papéis específicos para mulheres, alimentando a discussão contínua entre as mulheres sobre sua condição.

As discussões também avivam o sentimento de prazer pela resistência às imposições da sociedade patriarcal, acentuando tal resistência. A discussão pode também trazer à tona discordâncias com o roteiro e estimular diferentes maneiras de pressão direta e indireta sobre produtores de programas para que mudem o texto a fim de adaptá-lo aos valores da audiência. Brown acredita que, apesar de o discurso das redes de televisão não conduzir diretamente a uma ação política feminista, cria uma atitude crítica e de independência que encoraja as mulheres a se fortalecerem para a rotina da vida cotidiana na família e no trabalho e embasa mudanças graduais no papel da mulher na sociedade. 
Resumo: $\mathrm{O}$ artigo trata da Teoria da Recepção ou, como prefere o autor, Interpretaçāo da Audiência da midia, que busca compreender os processos comunicativos, a inter-relação emissores/receptores e a construçáo de significados pelos receptores. O autor aborda quatro tendências. A primeira delas é apresentada neste artigo e discute a tradição de Estudos Culturais e as contribuiçōes de autores como Raymond Williams e Stuart Hall, do Centro para Estudos de Cultura Contemporânea, de Birmingham, Inglaterra, para a consolidaçāo dessa linha teórica. Tem como pressuposto básico que os meios de comunicação não são meros meios de transporte de informação, mas revelam significados culturais criados num determinado período histórico. As outras tendências - Interacionismo Simbólico, Tradição dos Estudos de Consenso Cultural e Abordagem das Mediações e da Lógica de Produção e Consumo - serão apresentadas na próxima ediçāo.

Palavras-chave: recepçăo, audiência, meios de comunicação, Estudos Culturais
Abstract: The article deals with the Theory of Reception, or, as the author prefers, with the Audience's Interpretation of the media, that aims at understanding the communicative processes, the interrelationship emitters/receptors and the receptor's construction of meaning. The author covers four tendencies. The first of them is presented in this article and discusses the tradition of Cultural Studies and the contributions authors such as Raymond Williams e Stuart Hall, of the Center for Contemporaneous Culture, de Birmingham, England, have given to the consolidation of this theoretical line of thought. It has as its basic assumption that the mass communication are not mere means to transport information, but, instead, reveal cultural meanings created in a certain historical period. The other tendencies - Symbolic Interactionism, Cultural Consensus Study Tradition and the Logic of Production and Consumption - will be presented in the next edition.

Key words: reception, audience, mass communication, Cultural Studies 